\title{
Análise das diferenças na implantação do balanced scorecard nas maiores empresas da região sul do Brasil
}

\section{Analysis of the differences in the implementation of balanced scorecard in the major companies in southern Brazil}

\author{
Giseli Spessatto ${ }^{1}$ \\ Ilse Maria Beuren²
}

\begin{abstract}
Resumo: O estudo objetiva analisar se há diferenças significantes na implantação do Balanced Scorecard (BSC), quanto a dificuldades, impactos, efeitos e grau de utilização, entre as maiores empresas da região sul do Brasil. Para tal, realizou-se pesquisa descritiva, com abordagem quantitativa dos dados. A pesquisa foi realizada em 19 empresas da região sul listadas na Revista Valor 1000, edição de 2008, que utilizam ou estão implantando o BSC. Os resultados da pesquisa mostram que o processo de implantação do BSC nas empresas pesquisadas levou de um a quatro anos para ser concluído. A maior dificuldade enfrentada no processo foi mobilizar todas a trabalharem com o modelo. Como impacto mais representativo, prevaleceu que as medidas de desempenho definidas no BSC são capazes de diferenciar a estratégia da empresa tornando-a única e, como efeito mais significativo, foi apontado o foco na estratégia. A proposição com maior grau de utilização foi a de alinhar a organização com a estratégia. Para analisar as diferenças do grau de desenvolvimento do BSC nas empresas, consideraram-se dois grupos, as que implantaram um BSC corporativo com desdobramento para cada tema estratégico e as que implantaram um BSC único para toda a empresa, sendo que o primeiro grupo apresentou maiores dificuldades e maior grau de utilização. Conclui-se que há diferenças significantes na implantação do BSC entre as empresas pesquisadas, no que se refere a dificuldades de operacionalização e ao grau de utilização, e que não há diferenças nos impactos e efeitos ocasionados pelo BSC. Palavras-chave: Implantação. Balanced Scorecard. Empresas da região sul do Brasil.
\end{abstract}

\begin{abstract}
This study aims to investigate whether there are differences in the implementation of Balanced Scorecard (BSC) regarding the difficulties, impacts, effects, and extent of use between the largest companies in southern Brazil. Therefore, a descriptive research with quantitative approach to data was conducted in 19 southern companies that operate in the South of the country and were listed in the journal Valor 10002008 edition, which have already adopted or are implementing the BSC. The s results obtained show that the BSC implementing process in the companies studied took from one to four years to be completed. The greatest difficulty faced during the process implementation was to mobilize people involved to work according to the model. The most representative impact was that the performance measures defined in the BSC are able to differentiate the company's strategy making it unique and, and the most significant effect was the focus on strategy. The most commonly used proposition was to align the organization with the strategy. To analyze the differences in the BSC degree of development in the companies studied, two groups were considered: the ones that have implemented a BSC with corporate development for each strategic theme and the ones that have implemented a single enterprise-wide BSC; the first group showed the greatest difficulties and greater use. It can be Concluded that there are significant differences between in the BSC implementation andbetween the researched companies studied, with regard to operational difficulties and the degree of use, and that there isn't no difference in the effects caused by impacts andthe implementation of BSC.
\end{abstract}

Keywords: Implementation. Balanced scorecard. Southern Brazilian companies.

\footnotetext{
${ }^{1}$ Departamento de Ciências Contábeis, Universidade Regional de Blumenau - FURB, Rua Antônio da Veiga, 140, sala D 202, Victor Konder, CEP 89012-900, Blumenau, SC, Brasil, e-mail: difratelli@gegnet.com.br

2 Programa de Pós-graduação em Ciências Contábeis, Universidade Federal do Paraná - UFPR, Av. Prefeito Lothário Meissner, 632, Campus III, Jardim Botânico, CEP 80210-070, Curitiba, PR, Brasil, e-mail: ilse.beuren@ gmail.com
}

Recebido em 3/4/2011 — Aceito em 25/11/2012

Suporte financeiro: Nenhum. 


\section{Introdução}

Para as empresas manterem-se competitivas no mercado globalizado e de forte concorrência, precisam traçar estratégias que sejam compatíveis e assegurem sua continuidade. A procura por maior competitividade e aumento da capacidade de gerar lucros, aliada à crença dos executivos de que o uso exclusivo de medidas financeiras distorce a tomada de decisões, apontaram para a busca de um novo sistema de gestão em substituição às informações geradas pela contabilidade financeira.

Neste sentido, a contabilidade gerencial vem conquistando espaço à medida que busca subsidiar com informações os gestores na tomada de decisões. As informações gerenciais podem amparar as decisões dos gestores, para tornar as empresas mais competitivas em relação aos seus concorrentes e oferecer benefícios aos seus proprietários. A contabilidade gerencial dispõe de instrumentos voltados ao gerenciamento estratégico das organizações, entre os quais, pode-se citar o Balanced Scorecard (BSC).

O BSC foi concebido originalmente por Kaplan e Norton (1992) como um sistema equilibrado de medição estratégica, organizado em torno de quatro perspectivas distintas. Os autores sentiram-se motivados a criar esse instrumento porque consideravam os indicadores financeiros incapazes de refletir as atividades criadoras de valor relacionadas com os ativos intangíveis da organização. Com o passar do tempo os estudos foram evoluindo e o BSC transformando-se em um sistema gerencial essencial no processo sistemático de implementação e obtenção de feedback sobre a estratégia.

Assim, o BSC constitui-se em um sistema de gestão e medição de desempenho derivado das estratégias e capacidades das organizações (KAPLAN; NORTON, 1997). Conforme Teixeira (2003), o BSC apresenta-se como um modelo complementar no impasse entre a construção de capacidades competitivas de longo alcance (ativos intangíveis) e os informes obtidos por meio da contabilidade financeira.

O BSC tem como principal objetivo o alinhamento de toda a organização com suas estratégias. Conforme Kaplan e Norton (1997), ele complementa o planejamento à medida que traduz a missão e a visão da empresa em um conjunto de indicadores de desempenho estruturados em uma relação de causa e efeito e apoiados em torno de quatro perspectivas distintas. Serve de base para um sistema de medição e gestão estratégica ao possibilitar o acompanhamento e avaliação das estratégias empresariais.

Kaplan e Norton (2000) mencionam que a complexidade do gerenciamento nas organizações exige que os gestores tenham condições de visualizar o desempenho da empresa sob quatro perspectivas, a fim de entender: como a organização é vista pelos clientes (perspectiva dos clientes); no que deve ser excelente (perspectiva dos processos internos); se há capacidades de continuar melhorando e criando valor (perspectiva do aprendizado e crescimento); e como a organização é vista pelos acionistas (perspectiva financeira).

O BSC propõe-se a atender a uma antiga demanda por mecanismos que consigam integrar a estratégia com a operação e incorporar medidas não financeiras à avaliação de desempenho. Para Kaplan e Norton (2000, p. 176), “"...] a estratégia descrita numa forma mais disciplinada pode aumentar a probabilidade de sucesso na sua implementação".

No entanto, o processo de implantação do BSC constitui-se em uma tarefa complexa, uma vez que precisa estimular unidades de negócios a ligar seus objetivos financeiros à estratégia corporativa (KAPLAN; NORTON, 1997). O scorecard tem de contar a história da estratégia, começando com os objetivos financeiros a longo prazo e ligando-os a uma sequência de medidas que devem ser tomadas com relação aos processos financeiros, clientes, processos internos, empregados e sistemas.

Assim elaborou-se a seguinte questão-problema: Há diferenças na implantação do Balanced Scorecard (BSC), quanto a dificuldades, impactos, efeitos e grau de utilização, entre as maiores empresas da região sul do Brasil? O estudo objetiva analisar se há diferenças significantes na implantação do Balanced Scorecard (BSC), quanto a dificuldades, impactos, efeitos e grau de utilização, entre as maiores empresas da região sul do Brasil.

O BSC surgiu em 1990 com pesquisas de Robert S. Kaplan e David P. Norton, quando o Instituto Nolan Norton, unidade de pesquisa da KPMG, patrocinou um estudo de um ano em diversas empresas para buscar um novo método de mensuração do desempenho, para substituir os que estavam desatualizados (KAPLAN; NORTON, 1997). Passados 20 anos de sua concepção nos Estados Unidos e implantação em empresas do mundo todo, justifica-se este estudo que investiga dificuldades, impactos, efeitos e utilização em empresas brasileiras.

\section{Balanced Scorecard}

O Balanced Scorecard (BSC) tem o papel de fazer a informação estratégica fluir até os níveis operacionais. De acordo com Rocha (2002), sem o BSC, o orçamento torna-se o centro do processo de gestão e, assim, a empresa se apoia no controle financeiro, na visão a curto prazo e é orientada para as limitações. Kaplan e Norton (1997) defendem a integração entre o planejamento estratégico e o orçamento operacional para que a ação seja vinculada à visão da organização. No entanto, os autores alertam que a comunicação dos objetivos e medidas do BSC não é suficiente para obter o comprometimento de todos os membros. 
Para Kaplan e Norton (2000, p. 22),

[...] as organizações focadas na estratégia exigem que todos os empregados compreendam a estratégia e conduzam suas tarefas cotidianas de modo a contribuir para o êxito da estratégia.

Conforme Kaplan e Norton (1997), o principal objetivo do BSC é o alinhamento do planejamento estratégico com as ações operacionais da empresa por meio das seguintes ações: a) esclarecer e traduzir a visão e a estratégia; b) comunicar e associar objetivos e medidas estratégicos; c) planejar, estabelecer metas e alinhar iniciativas estratégicas; e d) melhorar o feedback e o aprendizado estratégico.

Costa (2001, p. 61) afirma que o BSC é um sistema que atua para desdobrar a estratégia em ações e gerenciar o seu cumprimento, possui como requisito básico a definição de uma estratégia coerente para a empresa. Sistematicamente, se caracteriza como um processo gerencial que atua no desdobramento da estratégia de cima para baixo, identifica os fatores-chave de desempenho organizados em quatro perspectivas de gestão, ligados entre si por relacionamentos de causa e efeito, e

[...] pela identificação dos indicadores e medidas que expressem adequadamente se as iniciativas estão produzindo os resultados esperados, encadeados de forma a cumprir a estratégia. (COSTA, 2001, p. 61).

A capacidade de aprendizado estratégico é obtida, conforme Prieto et al. (2006), pelo processo de feedback e aprendizado, tornando, dessa forma, a gestão estratégica um processo contínuo. O BSC permite que a organização monitore seus resultados a curto prazo nas quatro perspectivas, permitindo a modificação das estratégias em curso e refletindo o aprendizado organizacional. De acordo com Reis, Colauto e Pinheiro (2007), para que a estratégia se transforme em um processo contínuo necessita de acompanhamento contínuo a fim de que seja implementada. Qualquer aprendizado surgido diante de um fato novo deve ser considerado e recebido como uma inovação possível de implicar em mudança de imediato.

Em pesquisa realizada por Soares Junior e Prochnik (2004), foi constatado que a conversão da estratégia em processo contínuo, por meio da conexão entre orçamentos e estratégias, é um dos motivos apontados para a implantação do BSC por muitas das organizações estudadas. No entanto, isto ainda depende da superação da fase de refinamento do BSC e da consolidação da utilização de softwares de apoio com mais recursos. Uma vinculação mais direta entre BSC e orçamento, portanto, também passa por um aprendizado que consome algum tempo na utilização desse modelo de gestão.

\subsection{Aspectos dificultadores da implementação do BSC}

Os principais passos para a implementação de um BSC capaz de construir uma organização focalizada na estratégia são apontados por Kaplan e Norton (2000, p. 20), como segue: a) traduzir a estratégia em termos operacionais; b) alinhar a organização com a estratégia; c) transformar a estratégia em tarefa de todos; d) converter a estratégia em processo contínuo; e e) mobilizar a mudança por meio da liderança executiva.

Apesar de toda popularidade e sofisticação da teoria e prática relacionadas ao BSC, de acordo com Burlim e Cia (2007) a implementação é complexa, exige disponibilidade de recursos e contribuição de todos os funcionários para sua efetivação, motivos que expõem as empresas a diversos riscos que podem impedir o sucesso de seu projeto. Saheli (2002) destaca que, quanto menor a unidade, mais fácil será a implementação do BSC e a monitoração de seus resultados; por outro lado, quanto maior o número de unidades, mais complexo torna-se o processo, pois cresce também a diversidade de interesses.

Burlim e Cia (2007) apontam, com base em pesquisa realizada, alguns pontos principais em que as empresas encontram entraves na implementação do projeto de BSC:

- Definição de uma estratégia - dificuldade por parte dos gestores de entender a estratégia e a visão da organização;

- Envolvimento e comprometimento de todos os níveis - se a alta administração não se envolver ativamente no projeto, ao delegar a estratégia para níveis hierárquicos intermediários, corre o risco de que estes não estejam preparados para entender a estratégia ou o projeto do BSC como um todo;

- Escolha e alinhamento dos indicadores - estes devem ser desenvolvidos em sintonia com a estratégia definida, contar com o envolvimento de todos os líderes da empresa e apresentar as quatro perspectivas do BSC de forma balanceada; e

- BSC como um evento único e não como um processo contínuo - isso ocorre quando a organização não dá manutenção às informações do sistema BSC após a implementação realizada pela empresa de consultoria.

Kaplan e Norton (1997) afirmam que na implantação do BSC há uma incoerência entre a formulação e a implementação das estratégias, e que isso ocorre devido às barreiras criadas pelos sistemas gerenciais tradicionais, que foram feitos para: criar e comunicar a estratégia; alocar recursos; definir metas e direções; e fornecer feedback. Sugerem que as barreiras identificadas podem ser superadas com a integração 
do BSC ao novo sistema de gestão estratégica. São elas: visões e estratégias não executadas; estratégias não associadas às metas; estratégias não associadas à alocação de recursos; e feedback tático, não estratégico.

O BSC enfrenta dificuldades em sua implantação, segundo Epstein e Manzoni (1998), porque se configura como um processo que tem necessidade de introduzir mudanças na organização. Explicam que mudanças afetam a disponibilidade de informações relacionadas ao desempenho organizacional, podendo representar uma ameaça ao processo, principalmente se houver mudança no equilíbrio do poder na organização. Consideram como principais falhas na implementação do BSC os sistemas de medição mal projetados.

A ideia de que o BSC impõe uma mudança organizacional é compartilhada por Schneiderman (1999), ao afirmar que as organizações somente mudam quando os empregados se dispõem a compartilhar a propriedade das metas e dos meios. Para o autor, os principais motivos de falhas na implementação do BSC são: considerar as variáveis não financeiras como direcionadores primários da satisfação futura dos stakeholders; dificuldades na definição das medidas, negociação das metas ao invés de atenderem aos desejos dos stakeholders e a melhoria das capacidades dos processos; ausência de um sistema que comunique as metas de alto nível aos inferiores, dificultando o alinhamento da organização; e ausência de uma ligação entre o lado financeiro e o não financeiro do scorecard.

Fernandes e Fonseca (2006) identificaram em seu estudo obstáculos de origem cultural na implantação do BSC. Confrontando os elementos culturais americanos presentes no BSC com os elementos da cultura brasileira, indicaram características de empresas brasileiras:

- Preferem estabelecer objetivos voltados para grupos e equipes, atribuindo pouca ênfase a conquistas e realizações pessoais;

- Apresentam dificuldade em aplicar regras universais e em lidar com medidas quantitativas (critérios objetivos);

- Evitam a utilização de críticas no processo de comunicação de feedback para não ferir a harmonia do grupo;

- Alto grau de distância do poder dificulta a participação dos funcionários no processo de formulação da estratégia; e

- Ênfase nas relações pessoais e no status atribuído dificultam a avaliação com base no desempenho.

Por outro lado, Fernandes e Fonseca (2006, p. 11) detectaram um aspecto cultural que se mostra favorável à implantação do BSC:

[...] as empresas brasileiras levam em consideração conexões particularistas na tomada de decisão e aceitam critérios subjetivos no estabelecimento de planos de remuneração ligados às metas da organização. (FERNANDES; FONSECA, 2006, p. 11).

Os autores relatam que é importante no processo de implantação do BSC, que os executivos das empresas busquem identificar e compreender os elementos presentes na cultura organizacional, analisando a sua compatibilidade com os valores implícitos no BSC.

Kaplan e Norton (1997, p. 297) mencionam que existem várias maneiras pelas quais o projeto de scorecards pode fracassar, como:

[...] falhas na estrutura e na escolha das medidas para o scorecard, além de falhas organizacionais no processo de desenvolvimento do scorecard na sua forma de utilização.

De acordo com Lima (2006), o ponto de partida do desdobramento do BSC é o de alto nível, utilizado pela organização como um todo. Os objetivos e indicadores contidos nesse BSC são levados então ao próximo nível da organização, que, geralmente, compreende unidades de negócio. No terceiro nível do desdobramento, grupos e departamentos específicos desenvolvem scorecards baseados no scorecard da unidade de negócios. O nível final é o de equipes e individual.

\subsection{Críticas ao BSC}

Para Ahlert e Kronmeyer Filho (2004, p. 6), o BSC tem alavancado sua aceitação e utilização nas organizações pela utilização de métodos de desdobramento de objetivos e utilização de mecanismos gráficos de representação de relações de causa-efeito que em si não são absolutamente recursos inovadores, pois estão presentes em inúmeras propostas conceituais práticas no campo de gestão das organizações, anteriores ou contemporâneas à proposição do BSC. O seu mérito, de acordo com os autores,

[...] reside na adequada combinação destes métodos até então isolados ou usados em combinações menos integradas em outras propostas, constituindo uma proposta inovadora pela combinação destes elementos. (AHLERT; KRONMEYER FILHO, 2004, p. 6).

De acordo com Saheli (2002, p. 9),

[...] apesar de sua abordagem simples, o BSC é de difícil materialização. O grande gargalo do processo está nos sistemas computacionais para tratamento dos dados necessários à operacionalização da avaliação empresarial.

Para este problema, a autora oferece como alternativa a utilização de modelos semiestruturados de Business Intelligence. A organização requer disponibilidade de soluções para os níveis operacionais 
da organização, para então implementar soluções para níveis estratégicos. O desafio

[...] é juntar todas as informações em um aplicativo que as traduza em conhecimento estratégico relevante, considerando uma relação custo-benefício não desfavorável.

Bontis et al. (1999) consideram que o modelo baseado nas quatro perspectivas constitui um fator de rigidez do BSC. Mencionam que Kaplan e Norton citam a possibilidade de se expandir o número de perspectivas, caso existam ações críticas que possam suportar ou justificar tal expansão. Essa condição, de que o aumento do número de perspectivas, só deve ser feito quando existirem ações críticas justificando-o, revela-se uma camisa de força para o administrador e constitui-se em rigidez do modelo.

Outro ponto destacado por Norreklit (2000) é o fato de o BSC ser fundamentado principalmente em motivação externa. Ainda que este tipo de motivação seja importante para comunicar o comportamento desejado e que será recompensado dentro da organização, ele é insuficiente para fazer com que os indivíduos ajam de forma pró-ativa e sejam solucionadores criativos de problemas. É importante criar compromisso intrínseco por parte dos empregados. Quando o foco de motivação é externo, os empregados se empenham para alcançar os resultados nas áreas medidas, mas ficam indiferentes a outros elementos importantes.

O questionamento de Epstein e Manzoni (1998) relaciona-se à habilidade dos executivos em articular uma visão clara e comum da estratégia da empresa, capaz de permitir a construção do BSC. Os autores consideram que a definição da estratégia pode ser um processo difícil para os executivos de uma grande empresa. Em alguns casos, a estratégia pode não estar bem definida e, em outros, os membros da alta administração tendem a possuir opiniões diferentes sobre qual deve ser a estratégia da organização.

Costa (2001) assevera que a estratégia da empresa pode levar à fixação de padrões e metas que, necessariamente serão alcançados com mais facilidade por uns setores do que por outros setores da organização. Isso pode desestimular tanto os empregados dos setores em que a dificuldade é maior, quanto os empregados dos setores nos quais a dificuldade é menor e, consequentemente, não gerar o melhor desempenho dos empregados/organização.

Na visão de Fernandes (2002), o aprendizado estratégico deve se basear numa linguagem que supere as limitações dos arcabouços lineares e estáticos. Como o BSC simplifica as hipóteses de relações de causa e efeito para traduzir a estratégia, não considerando os efeitos de feedbacks e delays entre as medidas de desempenho, qualquer problema só pode ser identificado e vir à tona durante a implantação. Assim, o potencial de aprendizado estratégico pode ficar prejudicado e custar muito caro para a empresa.

\subsection{Benefícios do BSC}

Para Kaplan e Norton (2000), o BSC é um instrumento que possibilita identificar com mais facilidade a necessidade de implantação de novos programas, produtos e processos críticos para contrapor às novas ameaças que são comuns nas empresas que atuam em ambientes em rápida mutação. Incentiva o diálogo entre as unidades de negócios e os executivos da organização em relação aos objetivos a curto e longo prazos e é mais impactante em empresas que objetivam realizar mudanças organizacionais.

Em contraste com as dificuldades experimentadas pela maioria das organizações na implementação da estratégia, segundo Kaplan e Norton (2000), tais empresas utilizaram o BSC para promover grandes mudanças estratégicas e organizacionais. Com isso as empresas desfrutaram de benefícios substanciais com suas novas estratégias logo no início das atividades de implementação. Para os autores, o BSC foi o responsável pelo êxito, pois foi utilizado para concentrar todos os recursos organizacionais na nova estratégia.

O scorecard, de acordo com Kaplan e Norton (2000), capacitou organizações bem-sucedidas a construir um novo tipo de sistema gerencial, concebido para gerenciar a estratégia. Este novo sistema gerencial apresenta três dimensões distintas:

- Estratégia - a qual se converte no principal item da agenda organizacional. O BSC permitiu que as organizações descrevessem e comunicassem a estratégia de maneira compreensível e que servisse de base para a ação;

- Foco - se torna muito concentrado. Com o BSC como guia, todos os recursos e atividades da organização se alinham com a estratégia; e

- Organização - todo o pessoal se mobiliza para formas de atuação radicalmente novas. $\mathrm{O}$ BSC fornece a arquitetura para a formação de novos elos organizacionais entre as unidades de negócio, os serviços compartilhados e empregados.

Teixeira (2003) afirma que, da mesma forma que o BSC influencia no gerenciamento organizacional, a organização influencia a estrutura do BSC como um todo. Assim, há uma evolução de ambas as estruturas. O BSC se adapta à organização em que está sendo aplicado e a organização também se adapta e evolui com a utilização do BSC. Esse processo de evolução da empresa por meio do aprimoramento de sua gestão estratégica pode ser classificado como um ponto positivo promovido pelo BSC.

Os aspectos positivos relacionados com o BSC identificados por Teixeira (2003) são: a) evolução da empresa em seu processo de gestão; b) o uso do BSC simultaneamente com programas de melhoramento 
contínuo é possível e recomendável; e c) o uso do BSC como alternativa de medição dos ativos intangíveis abrange a mensuração do capital intelectual, um importante ativo da era do conhecimento.

Rocha e Beuren (2002) identificaram, por meio do depoimento do vice-presidente da empresa em que o estudo foi aplicado, que a maior contribuição apresentada pelo BSC foi a estratégia deixar de estar distante das pessoas operacionais. As pessoas passaram a ter vontade de realizar as atividades de suas áreas. O BSC atua como um mecanismo de comunicação e difusão da estratégia entre os diversos níveis organizacionais.

De acordo com Kallás (2003), a correta aplicação do BSC implica uma série de vantagens, como a integração de medidas financeiras e não financeiras, a comunicação e feedback da estratégia, o vínculo com planejamento e orçamento e maior foco e alinhamento organizacional. Outra contribuição levantada por Kallás (2003), em relação ao BSC, é o alinhamento de indicadores de resultado (lag indicators) com indicadores de tendência (lead indicators) de uma forma lógica e alinhada à estratégia.

Para Rezende (2006, p. 66), ao facilitar a percepção de congruência em torno das metas, o BSC diminuiria grande parte dos dilemas organizacionais sobre performance e recompensa, simulando um mercado interno em que os recursos seriam alocados em função da criação de valor e o compartilhamento dos resultados alcançados, por ser mais discutido e visível,

[...] levaria à: diminuição da ambiguidade, maior participação, redução da incerteza; percepção da organização como entidade; perenidade e prosperidade, derivadas de métricas e de incentivos que melhoram os rituais puramente de ordem financeira.

Para Costa (2001), o simples fato de o gestor ser obrigado a pensar sistematicamente nos relacionamentos de causa e efeito, a refletir sobre suposições subjacentes às estratégias, constitui uma vantagem em relação às praticas correntes de tomada de decisão sobre os resultados operacionais de curto prazo. O BSC parte da premissa de que a estratégia deve ser uma tarefa de todos. Dessa forma, Kaplan e Norton (2000, p. 22) afirmam que

[...] as organizações focadas na estratégia exigem que todos os empregados compreendam a estratégia e conduzam suas tarefas cotidianas de modo a contribuir para o êxito da estratégia.

\section{Procedimentos metodológicos}

Pesquisa descritiva foi realizada por meio de um levantamento ou survey com abordagem quantitativa dos dados. A pesquisa descritiva, de acordo com Vergara (2000, p. 47),
[...] expõe características de determinada população ou de determinado fenômeno. Pode também estabelecer correlações entre variáveis e definir sua natureza. Não tem compromisso de explicar os fenômenos que descreve, embora sirva de base para tal explicação.

Levantamentos, conforme Martins e Theóphilo (2007, p. 60),

[...] são próprios para os casos em que o pesquisador deseja responder a questões acerca da distribuição de uma variável ou das relações entre características de pessoas ou grupos, da maneira como ocorrem em situações naturais.

Podem ser aplicados no estudo de relações entre variáveis, inclusive de causa e efeito, mas são mais indicados para a análise de fatos e descrições.

Quanto à abordagem do problema, este estudo apoia-se na análise quantitativa. Richardson $(1989$, p. 29) destaca que a abordagem quantitativa

[...] caracteriza-se pelo emprego da quantificação tanto nas modalidades de coleta de informações, quanto no tratamento dessas através de técnicas estatísticas desde as mais simples às mais complexas, como coeficiente de correlação, análise de regressão etc.

Acrescenta que as pesquisas que adotam o método quantitativo, em princípio, têm a intenção de garantir a precisão dos resultados, evitando distorções de análise, além de possibilitar maior margem de segurança quanto às inferências.

$\mathrm{O}$ universo definido para este estudo compreende as empresas que integram a lista das 1000 maiores empresas do Brasil, de acordo com a Revista Valor 1000, edição de setembro de 2008. A população corresponde às empresas desta lista localizadas na região sul do Brasil, em um número total de 192 empresas. Em cada uma destas empresas, entrou-se em contato com o setor de contabilidade, para verificar o nome e endereço eletrônico do respondente.

Das 192 empresas contatadas, 57 alegaram não ter autorização para participar da pesquisa, sendo assim, a população foi reduzida para 135 empresas, que disponibilizaram seu e-mail e aceitaram participar da pesquisa. Para estas, foi enviado o instrumento de coleta de dados da primeira fase da pesquisa (uma sondagem), que consistiu apenas em identificar quais empresas da população utilizam ou estão implantando o BSC. Foram obtidas 112 respostas, sendo que destas, 31 empresas utilizam ou estão implantando o BSC.

Das 31 empresas, 19 responderam ao instrumento de pesquisa da segunda etapa. Portanto, a amostra por acessibilidade compõe-se de 19 empresas, o que representa $61,29 \%$ do total das 31 empresas que possuem o BSC implantado ou estão em fase 
de implantação. Gil (2008, p. 100) define a amostra como o " "...] subconjunto do universo ou da população, por meio da qual se estabelecem ou se estimam as características desse universo ou população".

A opção pelo questionário foi motivada por ser um instrumento comum para a coleta de dados em pesquisas sociais. O questionário da segunda fase da pesquisa apresenta inicialmente uma pergunta sobre o início e conclusão da implantação do BSC e outra sobre a sua configuração. Seguem-se quatro blocos de perguntas em escala tipo Likert, cada um com um conjunto de itens, extraídos da revisão de literatura, apresentados em forma de afirmações, para o respondente expressar sua opinião, escolhendo um dos cinco pontos da escala. Investigaram-se, nos blocos, as dificuldades de operacionalização do BSC na empresa, impactos e efeitos decorrentes de sua implantação e o grau de utilização do BSC.

Um teste piloto foi realizado com um aluno de mestrado, que utiliza o BSC na empresa em que trabalha, e um profissional de mercado, que participou da implantação do BSC em sua empresa. Nenhum deles trabalha nas empresas que compõem a população da pesquisa. A confiabilidade de cada item do instrumento de pesquisa foi conferida com aplicação do Alfa de Cronbach, que demonstrou uma significância acima de 0,8202 para todos os itens. Para o envio do questionário, utilizou-se o software LimeSurvey, que envia o questionário por meio de um link para todos os endereços eletrônicos cadastrados.

A análise dos dados deu-se por meio de estatística descritiva, basicamente frequência e medidas centrais. Também foi realizado um teste estatístico de comparação entre médias, com bicaudal direta e utilização da tábua de TC (T crítico). Este teste foi aplicado para verificar se empresas que implantaram um BSC corporativo com desdobramento para cada tema estratégico (BSCC) se diferenciam das que implantaram um BSC único para toda a empresa (BSCU); se apresentaram diferenças quanto a dificuldades, impactos, efeitos e grau de utilização do BSC. Aplicou-se também a técnica estatística da análise das componentes principais nas variáveis tempo de implantação, dificuldades de operacionalização, impactos, efeitos e grau de utilização do BSC, para depois verificar as correlações canônicas entre grupos de variáveis.

\section{Apresentação e análise dos dados da pesquisa}

Nesta seção, descrevem-se os resultados da pesquisa sobre o BSC. Primeiramente destacam-se as datas de início e conclusão da implantação do projeto do BSC e a configuração do BSC na empresa. Na sequência, abordam-se as dificuldades enfrentadas pelas empresas na operacionalização do BSC, os impactos e efeitos decorrentes de sua adoção, o grau de utilização do BSC como instrumento de suporte ao processo de gestão e as diferenças significantes na implantação do BSC nas empresas pesquisadas.

$\mathrm{O}$ tempo que as empresas pesquisadas levaram para concluir o projeto de implantação do BSC, com vistas a identificar o projeto implantado mais antigo e o mais recente, é apresentado na Figura 1, sendo que as 19 empresas participantes da pesquisa estão representadas por letras de $\mathrm{A}$ a $\mathrm{S}$.

Nota-se, na Figura 1, que as empresas levaram de um a cinco anos para concluir a implantação do projeto do BSC. Não se pode afirmar com precisão o tempo, uma vez que os respondentes informaram

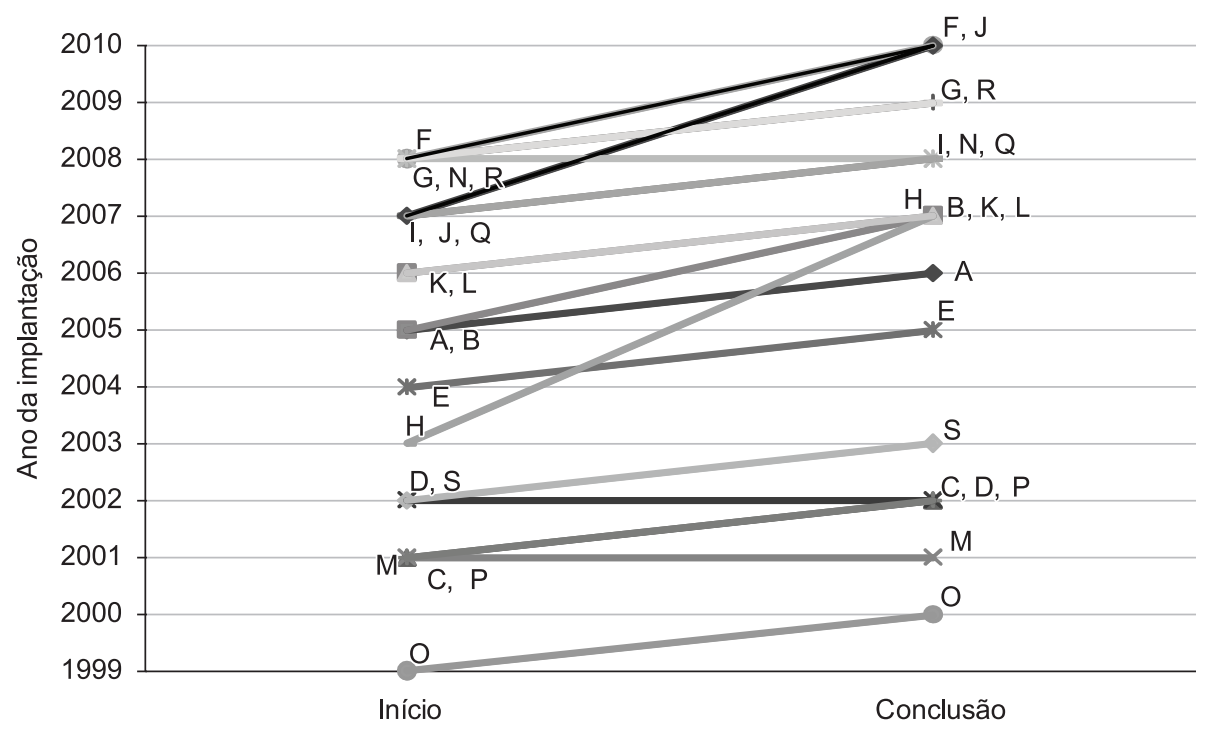

Figura 1. Data de início e de conclusão da implantação do BSC nas empresas. Fonte: dados da pesquisa. 
somente o ano, sem indicação do número de meses que cada empresa levou para concluir a implantação do projeto do BSC. A empresa O é a que introduziu o BSC há mais tempo - o projeto foi implantado no período de 1999 a 2000 -, enquanto que a empresa R é a que implantou o BSC mais recentemente - concluiu o projeto em 2009. As empresas F e $\mathrm{G}$ estavam em fase de implantação no período da coleta dos dados da pesquisa.

Para verificar a configuração do BSC, foi perguntado se a empresa possui implementado um BSC corporativo e um desdobramento do BSC para cada tema estratégico ou um BSC único para toda a empresa. Na Tabela 1, apresenta-se a configuração do BSC em cada empresa pesquisada.

Quanto à configuração do BSC, verifica-se, na Tabela 1, que 57,89\% das empresas possuem um BSC corporativo com desdobramento do BSC para cada tema estratégico; e 42,11\% das empresas possuem um BSC único para toda a empresa.

\subsection{Dificuldades enfrentadas na implantação do BSC com a sua operacionalização}

Para verificação das maiores dificuldades enfrentadas pelas empresas pesquisadas na operacionalização do BSC, foram listadas proposições para serem indicadas de acordo com o nível de relevância identificado em cada empresa $(0=$ Nenhum; 1=Pouco; 2=Intermediário; 3=Elevado; e 4=Muito elevado). Na Tabela 2, apresenta-se a classificação das dificuldades indicadas pelas empresas para a implementação do BSC.

Com relação às dificuldades enfrentadas pelas empresas pesquisadas para operacionalização do BSC, observa-se, na Tabela 2, que nenhuma das dificuldades elencadas foi apontada como muito elevada. Pela média calculada a partir das considerações de cada respondente, com variação entre 2,42 e 2,63, as dificuldades mais relevantes foram: mobilizar todos a trabalharem com o modelo; definir e tornar claro para todos a visão e a missão da organização, obtendo consenso geral em torno da estratégia a longo prazo; identificar indicadores; divulgar e implementar a estratégia em todos os níveis da organização; alinhar as metas individuais e departamentais com a estratégia das respectivas unidades de negócio.
Considerando-se as complexidades que o BSC pode gerar nas empresas, não era de se esperar o surgimento de poucas dificuldades durante o processo de implantação, bem como após estar implantado. Porém, surpreendeu o fato do grau de dificuldade ter-se apresentado com uma mediana igual ou menor do que 3, uma vez que, conforme constatado na literatura, várias pesquisas se dedicam a investigar as dificuldades encontradas no processo.

Conforme exposto por Kaplan e Norton (2000), em contrapartida às dificuldades encontradas pelas empresas, as que conseguem superá-las e tornar o BSC um processo contínuo dentro da organização, podem desfrutar de benefícios substanciais logo no início das atividades de implementação. Esta assertiva sugere que a organização que consegue adotar e se adaptar ao BSC usufrui de vantagem competitiva em relação às demais, pois estará concentrando seus recursos em uma estratégia consistente.

As proposições apontadas com menor grau de dificuldade foram: a "postura de espectador", presente nos funcionários, prejudica o comportamento pró-ativo e inovador; vincular o BSC com o orçamento; obter dados necessários para operacionalização dos indicadores; resistência dos funcionários; falta de comprometimento das pessoas envolvidas no processo; e interpretar os dados gerados no BSC.

Quanto ao comprometimento dos envolvidos com o processo, não há como afirmar precisamente, mas, devido ao fato de $47,37 \%$ das empresas pesquisadas não terem contratado consultoria externa para implementar o BSC, é possível que isso possa ter contribuído para o comprometimento dos empregados envolvidos no processo, uma vez que o resultado da implementação dependia, em grande parte, deles próprios.

Quanto à vinculação do BSC com o orçamento, Kaplan e Norton (2000) argumentam que a ideia principal no BSC é concentrar os processos críticos gerenciais, entre estes, o orçamento, em torno da estratégia da empresa. Desta forma, o scorecard poderia substituir o orçamento como centro dos processos gerenciais. A compatibilidade entre o scorecard e o orçamento pode assegurar que o esforço dedicado no desenvolvimento do BSC gere benefícios tangíveis à organização. $\mathrm{O}$ fato de sua vinculação com o BSC ter apresentado poucas dificuldades é

Tabela 1. Configuração do BSC nas empresas pesquisadas.

\begin{tabular}{lcc}
\hline \multicolumn{1}{c}{ Configuração do BSC } & $\mathbf{N}^{\circ}$ Empresas & \% \\
\hline BSC corporativo com desdobramento do BSC para cada tema estratégico & 11 & 57,89 \\
BSC único para toda a empresa & 8 & 42,11 \\
Total & $\mathbf{1 9}$ & $\mathbf{1 0 0 , 0 0}$ \\
\hline
\end{tabular}

Fonte: dados da pesquisa. 
um aspecto que pode contribuir para o sucesso de sua implantação.

A maioria das dificuldades arroladas foi identificada como intermediária e nenhuma empresa apontou outras dificuldades encontradas no processo de implantação. A continuidade do BSC na empresa depende de constante avaliação para que possíveis modificações necessárias sejam identificadas, garantindo assim que o instrumento seja útil à gestão estratégica da empresa. Soares Junior e Prochnik (2004) chamam atenção para o desafio de gerenciar a rotina do BSC, já que bons resultados não devem ser passíveis de acomodação.

As dificuldades apontadas pelos respondentes que mais se distanciaram do centro da amostra, ou

Tabela 2. Dificuldades relacionadas com a operacionalização do BSC.

\begin{tabular}{|c|c|c|c|c|c|c|c|c|c|}
\hline Dificuldades & $\begin{array}{l}\text { 国 } \\
\text { Z } \\
\text { Z } \\
\end{array}$ & 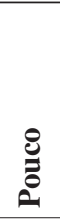 & 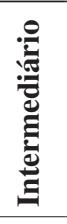 & 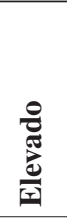 & 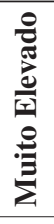 & 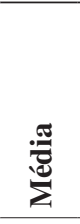 & 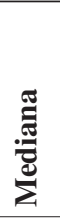 & $\frac{\pi}{g}$ & 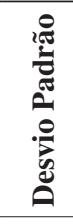 \\
\hline Mobilizar todos a trabalharem com o modelo & 1 & 2 & 3 & 10 & 3 & 2,63 & 3 & 3 & 1,04 \\
\hline $\begin{array}{l}\text { Definir e tornar claro para todos a visão e a missão da } \\
\text { organização, obtendo consenso geral em torno da estratégia } \\
\text { de longo prazo }\end{array}$ & 0 & 3 & 6 & 7 & 3 & 2,53 & 3 & 3 & 0,94 \\
\hline Identificar indicadores & 1 & 2 & 5 & 9 & 2 & 2,47 & 3 & 3 & 0.99 \\
\hline $\begin{array}{l}\text { Divulgar e implementar a estratégia em todos os níveis da } \\
\text { organização }\end{array}$ & 1 & 5 & 4 & 3 & 6 & 2,42 & 2 & 4 & 1,31 \\
\hline $\begin{array}{l}\text { Alinhar as metas individuais e departamentais com a } \\
\text { estratégia das respectivas unidades de negócio }\end{array}$ & 1 & 4 & 4 & 6 & 4 & 2,42 & 3 & 3 & 1,18 \\
\hline $\begin{array}{l}\text { Gerenciar efetivamente por meio de processos } \\
\text { multifuncionais }\end{array}$ & 1 & 2 & 7 & 7 & 2 & 2,37 & 2 & 2 & 0,98 \\
\hline $\begin{array}{l}\text { Quantificar as relações de causa e efeito estabelecidas entre } \\
\text { as medidas de desempenho }\end{array}$ & 1 & 2 & 9 & 3 & 4 & 2,37 & 2 & 2 & 1,09 \\
\hline Elaborar o plano de implementação & 0 & 5 & 6 & 5 & 3 & 2,32 & 2 & 2 & 1,03 \\
\hline Definir metas & 1 & 4 & 4 & 8 & 2 & 2,32 & 3 & 3 & 1,08 \\
\hline Conciliar as análises estratégicas às operacionais & 0 & 3 & 9 & 6 & 1 & 2,26 & 2 & 2 & 0,78 \\
\hline $\begin{array}{l}\text { Facilitar as análises críticas periódicas e sistemáticas do } \\
\text { desempenho em relação à estratégia adotada }\end{array}$ & 1 & 4 & 7 & 4 & 3 & 2,21 & 2 & 2 & 1,10 \\
\hline Construir o mapa estratégico & 0 & 3 & 9 & 7 & 0 & 2,21 & 2 & 2 & 0,69 \\
\hline $\begin{array}{l}\text { Alinhamento de indicadores de resultado (lag indicators) } \\
\text { com indicadores de tendência (lead indicators) de forma } \\
\text { lógica e alinhada à estratégia }\end{array}$ & 0 & 3 & 9 & 7 & 0 & 2,21 & 2 & 2 & 0,69 \\
\hline $\begin{array}{l}\text { Desdobramento do scorecard de nível superior em } \\
\text { scorecards de níveis inferiores }\end{array}$ & 1 & 3 & 9 & 4 & 2 & 2,16 & 2 & 2 & 0,99 \\
\hline $\begin{array}{l}\text { Criar a capacidade de identificar oportunidades e orientar as } \\
\text { iniciativas }\end{array}$ & 1 & 4 & 7 & 5 & 2 & 2,16 & 2 & 2 & 1,04 \\
\hline $\begin{array}{l}\text { Obter feedback de modo a poder introduzir em tempo as } \\
\text { melhorias estratégicas que necessitem de formulação }\end{array}$ & 1 & 3 & 8 & 6 & 1 & 2,16 & 2 & 2 & 1,04 \\
\hline Construção de uma base para um sistema de incentivos & 3 & 5 & 3 & 3 & 5 & 2,11 & 2 & 1 & 1,45 \\
\hline Definir os objetivos estratégicos & 1 & 3 & 8 & 7 & 0 & 2,11 & 2 & 2 & 0,85 \\
\hline Formalizar o sistema de informações & 1 & 5 & 8 & 3 & 2 & 2,00 & 2 & 2 & 1,05 \\
\hline Alocar tempo ao BSC na tomada de decisões & 0 & 5 & 9 & 5 & 0 & 2,00 & 2 & 2 & 0,73 \\
\hline $\begin{array}{l}\text { A "postura de espectador", presente nos funcionários, } \\
\text { prejudica o comportamento pró-ativo e inovador }\end{array}$ & 3 & 4 & 5 & 6 & 1 & 1,89 & 2 & 3 & 1,17 \\
\hline Vincular o BSC com o Orçamento & 2 & 5 & 8 & 2 & 2 & 1,84 & 2 & 2 & 1,27 \\
\hline Obter dados necessários para operacionalização dos indicadores & 2 & 6 & 6 & 4 & 1 & 1,79 & 2 & 1 & 1,05 \\
\hline Resistência dos funcionários & 1 & 8 & 5 & 4 & 1 & 1,79 & 2 & 1 & 1,03 \\
\hline Falta de comprometimento das pessoas envolvidas no processo & 1 & 10 & 3 & 2 & 3 & 1,79 & 1 & 1 & 1,24 \\
\hline Interpretar os dados gerados no BSC & 1 & 8 & 7 & 3 & 0 & 1,63 & 2 & 1 & 0,81 \\
\hline
\end{tabular}

Fonte: dados da pesquisa. 
seja, que podem ser consideradas muito difíceis por algumas empresas e pouco difíceis por outras, foram: construção de uma base para um sistema de incentivos; divulgar e implementar a estratégia em todos os níveis da organização; vincular o BSC com o orçamento; falta de comprometimento das pessoas envolvidas no processo; alinhar as metas individuais e departamentais com a estratégia das respectivas unidades de negócio; e a postura de espectador presente nos funcionários, prejudica o comportamento pró-ativo e inovador.

\subsection{Impactos decorrentes da adoção do BSC nas empresas pesquisadas}

Na Tabela 3, são listados os impactos ocasionados pela adoção do BSC nas empresas pesquisadas ( $0=$ Discordo Plenamente; $1=$ Discordo Parcialmente; 2=Nem Concordo, Nem Discordo; 3=Concordo Parcialmente; e 4=Concordo Plenamente).

Observa na Tabela 3 que o impacto mais representativo listado pelas empresas foi que as medidas de desempenho definidas no BSC são capazes de diferenciar a estratégia da empresa, tornando-a única. Esta proposição teve impacto muito elevado, com média de 3,21 , sendo que cinco empresas concordam plenamente, 13 concordam parcialmente, e uma empresa mostrou-se indiferente. Esta afirmação chama atenção para o fato da possibilidade das empresas que utilizam o BSC terem maior facilidade em manter-se competitivas, uma vez que ser diferente das demais contribui positivamente para que se destaquem.

Na sequência, as empresas apontaram outro impacto elevado decorrente da adoção do BSC, o resultado de um modelo consensual entre os gestores. Com média menor que 3 , aparecem as proposições: a implantação do BSC gerou forte choque na cultura da empresa; e as relações de causa e efeito tendem a simplificar a realidade; são lineares, unidirecionais e demoram a ser revistas.

Entre os impactos ocasionados pelo BSC, a proposição com menor consenso entre as empresas analisadas foi: a implantação do BSC gerou forte choque na cultura da empresa. Enquanto algumas empresas concordam apontando média 3 e 4, outras discordam, apontando média 0 e 1, e outras, ainda, mostram-se indiferentes.

\subsection{Efeitos decorrentes da adoção do BSC nas empresas pesquisadas}

Identificou-se também a impressão que a empresa obteve após a implantação do BSC. Na Tabela 4, são listados os efeitos decorrentes da implementação do BSC $(0=$ Nenhum; 1=Pouco; 2=Intermediário; 3=Elevado; e 4=Muito elevado).

Nota-se, na Tabela 4, que os efeitos mais relevantes sentidos pelas empresas com a implementação do BSC, com média entre elevado e muito elevado, são: foco na estratégia; elaboração do planejamento; foco no cliente; análise de desempenho da empresa; motivação e comprometimento das pessoas com o processo da estratégia; e priorização de projetos e ações.

Os efeitos sentidos pelas empresas pesquisadas coadunam com os preceitos de Kaplan e Norton (1997) ao afirmarem que o BSC traduz a visão e a estratégia da empresa em um conjunto coerente de medidas de desempenho. Kaplan e Norton (2000) aduzem que o BSC motiva para transformar a estratégia em tarefa de todos ao explicitar que o BSC é um sistema gerencial capaz de focalizar toda a empresa na estratégia e, ainda, quando alegam que o BSC possui três dimensões: estratégia, foco e organização.

Conforme Kaplan e Norton (2000, p. 22), organizações focadas possuem uma organização interna que exige compreensão e comprometimento

Tabela 3. Impactos decorrentes da adoção do BSC.

\begin{tabular}{|c|c|c|c|c|c|c|c|c|c|}
\hline Impactos & 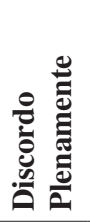 & 总 & 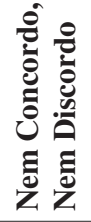 & 夈 & 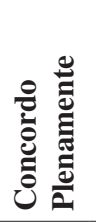 & 递 & 莺 & $\stackrel{\frac{\pi}{0}}{\stackrel{0}{g}}$ & 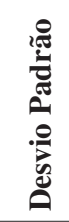 \\
\hline $\begin{array}{l}\text { As medidas de desempenho definidas no BSC são } \\
\text { capazes de diferenciar a estratégia da empresa, } \\
\text { tornando-a única }\end{array}$ & 0 & 0 & 1 & 13 & 5 & 3,21 & 3 & 3 & 0,52 \\
\hline $\begin{array}{l}\text { O BSC resultou de um modelo consensual entre } \\
\text { os gestores }\end{array}$ & 1 & 0 & 1 & 12 & 5 & 3,05 & 3 & 3 & 0,87 \\
\hline $\begin{array}{l}\text { A implantação do BSC gerou forte choque na } \\
\text { cultura da empresa }\end{array}$ & 2 & 3 & 3 & 8 & 3 & 2,37 & 3 & 3 & 1,21 \\
\hline $\begin{array}{l}\text { As relações de causa e efeito tendem a simplificar } \\
\text { a realidade; são lineares, unidirecionais e } \\
\text { demoram a ser revistas }\end{array}$ & 2 & 4 & 2 & 9 & 2 & 2,26 & 3 & 3 & 0,67 \\
\hline
\end{tabular}

Fonte: dados da pesquisa. 
Tabela 4. Efeitos decorrentes da adoção do BSC.

\begin{tabular}{|c|c|c|c|c|c|c|c|c|c|}
\hline Efeitos & $\begin{array}{l}\text { E } \\
\text { E } \\
\text { Z }\end{array}$ & $\stackrel{\circlearrowright}{\ddot{E}}$ & 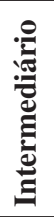 & 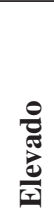 & 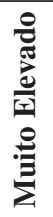 & 总 & 胥 & 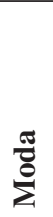 & 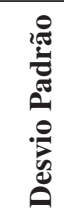 \\
\hline Foco na estratégia & 0 & 0 & 1 & 11 & 7 & 3,32 & 3 & 3 & 0,57 \\
\hline Elaboração do planejamento & 1 & 0 & 2 & 9 & 7 & 3,11 & 3 & 3 & 0,97 \\
\hline Foco no cliente & 1 & 0 & 2 & 10 & 6 & 3,05 & 3 & 3 & 0,94 \\
\hline Análise de desempenho da empresa & 1 & 0 & 1 & 12 & 5 & 3,05 & 3 & 3 & 0,87 \\
\hline $\begin{array}{l}\text { Motivação e o comprometimento das pessoas com o } \\
\text { processo da estratégia }\end{array}$ & 0 & 0 & 5 & 9 & 5 & 3,00 & 3 & 3 & 0,73 \\
\hline Priorização de projetos e ações & 0 & 1 & 2 & 12 & 4 & 3,00 & 3 & 3 & 0,73 \\
\hline Melhora na tomada de decisões & 1 & 0 & 2 & 12 & 4 & 2,95 & 3 & 3 & 0,87 \\
\hline $\begin{array}{l}\text { Participação dos gestores e empregados nas discussões } \\
\text { acerca da estratégia e sua implementação }\end{array}$ & 0 & 0 & 5 & 10 & 4 & 2,95 & 3 & 3 & 0,67 \\
\hline Alinhamento das ideias dos gestores & 1 & 0 & 4 & 10 & 4 & 2,84 & 3 & 3 & 0,93 \\
\hline Foco no aprendizado e crescimento & 0 & 0 & 6 & 10 & 3 & 2,84 & 3 & 3 & 0,67 \\
\hline Foco em inovação de processos internos & 0 & 0 & 7 & 9 & 3 & 2,79 & 3 & 3 & 0,69 \\
\hline Resultados da empresa a longo prazo & 2 & 0 & 4 & 8 & 5 & 2,74 & 3 & 3 & 1,16 \\
\hline Objetividade da comunicação interna & 1 & 0 & 6 & 8 & 4 & 2,74 & 3 & 3 & 0,96 \\
\hline Execução do plano & 1 & 1 & 3 & 13 & 1 & 2,63 & 3 & 3 & 0,87 \\
\hline Elaboração do orçamento & 2 & 3 & 2 & 8 & 4 & 2,47 & 3 & 3 & 1,27 \\
\hline Sistema de gestão baseado em valor para o acionista & 1 & 1 & 7 & 8 & 2 & 2,47 & 3 & 3 & 0,94 \\
\hline Avaliação de desempenho das pessoas & 2 & 2 & 4 & 9 & 2 & 2,37 & 3 & 3 & 1,13 \\
\hline Minimização da carga de informações a analisar & 2 & 1 & 9 & 5 & 2 & 2,21 & 2 & 2 & 1,05 \\
\hline Cumprimento do orçamento & 3 & 2 & 3 & 9 & 2 & 2,21 & 3 & 3 & 1,25 \\
\hline
\end{tabular}

Fonte: dados da pesquisa.

de todos os funcionários de modo a contribuir para o êxito da estratégia. Depreende-se que o BSC inibe a falta de envolvimento com o planejamento estratégico à medida que parte da premissa de que a estratégia deve ser uma tarefa de todos.

Entre as proposições sugeridas, as que foram apontadas com menor efeito são: avaliação de desempenho das pessoas; minimização da carga de informações a analisar; e cumprimento do orçamento.

Elaboração do orçamento, cumprimento do orçamento, resultados da empresa a longo prazo e avaliação de desempenho das pessoas foram as proposições que mais destoaram quanto a opinião das empresas. Enquanto algumas acreditam que seu efeito foi elevado, outras acreditam não terem apresentado efeito algum.

\subsection{Grau de utilização do BSC como instrumento de suporte ao processo de gestão}

Buscou-se também verificar o grau de utilização do BSC como instrumento de suporte ao processo de gestão. Na Tabela 5, estão listados alguns itens e a importância que as empresas atribuíram a cada item.

Na Tabela 5, nota-se que as proposições com maior grau de utilização listadas pelos respondentes são: alinhar a organização com a estratégia; criar um sistema de apoio à decisão; criar um sistema de medição de desempenho; esclarecer e traduzir a visão e a estratégia; definir metas e priorizar iniciativas; criar um sistema de gestão estratégica; busca de sinergia organizacional; e engajamento e determinação da alta gestão, envolvimento da presidência com a comunicação da estratégia.

As proposições identificadas com menor grau de utilização foram: melhoria no diálogo entre os gestores e colaboradores dos vários níveis hierárquicos; maximizar o lucro; atender à gestão da qualidade; vincular a estratégia com o planejamento e o orçamento; conquistar vantagem competitiva, liderança de mercado; e alinhar os objetivos individuais com a estratégia corporativa.

Verifica-se que o BSC está sendo utilizado pelas empresas pesquisadas como um sistema de gestão estratégica, de medição de desempenho e de apoio 
Tabela 5. Grau de utilização do BSC nas empresas pesquisadas.

\begin{tabular}{|c|c|c|c|c|c|c|c|c|c|}
\hline Itens & $\begin{array}{l}\text { 园 } \\
\text { 三 } \\
\text { 乙 }\end{array}$ & $\stackrel{\mathscr{U}}{0}$ & 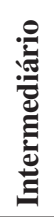 & $\begin{array}{l}\frac{0}{\pi} \\
\frac{\partial}{2} \\
\frac{\partial}{x}\end{array}$ & 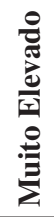 & 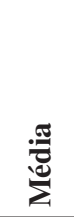 & 茎 & $\stackrel{\frac{\pi}{0}}{\Sigma}$ & 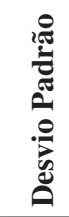 \\
\hline Alinhar a organização com a estratégia & 0 & 0 & 3 & 4 & 12 & 3,47 & 4 & 4 & 0,77 \\
\hline Criar um sistema de apoio à decisão & 0 & 0 & 1 & 10 & 8 & 3,37 & 3 & 3 & 0,58 \\
\hline Criar um sistema de medição de desempenho & 0 & 0 & 2 & 9 & 8 & 3,32 & 3 & 3 & 0,65 \\
\hline Esclarecer e traduzir a visão e a estratégia & 0 & 0 & 2 & 10 & 7 & 3,26 & 3 & 3 & 0,65 \\
\hline Definir metas e priorizar iniciativas & 0 & 0 & 2 & 9 & 8 & 3,26 & 3 & 3 & 0,65 \\
\hline Criar um sistema de gestão estratégica & 1 & 0 & 0 & 10 & 8 & 3,26 & 3 & 3 & 0,91 \\
\hline Busca de sinergia organizacional & 0 & 0 & 3 & 9 & 7 & 3,21 & 3 & 3 & 0,69 \\
\hline $\begin{array}{l}\text { Engajamento e determinação da alta gestão, envolvimento da } \\
\text { presidência com a comunicação da estratégia }\end{array}$ & 0 & 0 & 2 & 11 & 6 & 3,21 & 3 & 3 & 0,61 \\
\hline Crescer de forma sustentada a longo prazo & 1 & 0 & 2 & 8 & 8 & 3,16 & 3 & 3 & 0,99 \\
\hline Comunicar e associar objetivos e medidas estratégicas & 0 & 0 & 1 & 14 & 4 & 3,16 & 3 & 3 & 0,49 \\
\hline Incrementar o desempenho financeiro da organização & 0 & 1 & 2 & 10 & 6 & 3,11 & 3 & 3 & 0,79 \\
\hline Disciplinar o processo de formação da estratégia & 0 & 0 & 4 & 9 & 6 & 3,11 & 3 & 3 & 0,72 \\
\hline Melhorar o processo de tomada de decisões & 1 & 0 & 3 & 8 & 7 & 3,05 & 3 & 3 & 1 \\
\hline $\begin{array}{l}\text { Transmitir a visão estratégica da alta direção para toda a } \\
\text { organização }\end{array}$ & 1 & 0 & 3 & 8 & 7 & 3,05 & 3 & 3 & 1 \\
\hline Ligar sua visão de futuro com o trabalho das pessoas & 0 & 0 & 3 & 13 & 3 & 3,00 & 3 & 3 & 0,56 \\
\hline $\begin{array}{l}\text { Melhoria no diálogo entre os gestores e colaboradores dos } \\
\text { vários níveis hierárquicos }\end{array}$ & 1 & 0 & 2 & 12 & 4 & 2,95 & 3 & 3 & 0,89 \\
\hline Maximizar o lucro & 1 & 1 & 4 & 6 & 7 & 2,89 & 3 & 4 & 1,12 \\
\hline Atender à gestão da qualidade & 1 & 3 & 2 & 8 & 5 & 2,68 & 3 & 3 & 1,03 \\
\hline Vincular a estratégia com o planejamento e o orçamento & 2 & 1 & 4 & 7 & 5 & 2,63 & 3 & 3 & 1,22 \\
\hline Conquistar vantagem competitiva, liderança de mercado & 2 & 1 & 3 & 9 & 4 & 2,63 & 3 & 3 & 1,17 \\
\hline Alinhar os objetivos individuais com a estratégia corporativa & 1 & 2 & 5 & 7 & 4 & 2,58 & 3 & 3 & 1,09 \\
\hline
\end{tabular}

Fonte: dados da pesquisa.

à decisão, para esclarecer e traduzir a visão e a estratégia e para alinhar a organização com a estratégia. Costa (2001) afirma que o BSC é um sistema que atua para desdobrar a estratégia em ações e gerenciar seu cumprimento e que possui como requisito básico a definição de uma estratégia coerente para a empresa.

Pelos resultados obtidos, pode-se afirmar que a utilidade do BSC está vinculada com a operacionalização da estratégia, conforme constatado por Rocha (2002) e de acordo com os preceitos identificados por Kaplan e Norton $(1997,2000)$ sobre a utilização do BSC como um sistema de gestão capaz de alinhar a estratégia organizacional.

As proposições de uso que apresentaram maior dispersão entre os apontamentos realizados pelos respondentes, conforme se pode verificar, por meio do cálculo do desvio padrão, foram: vincular a estratégia com o planejamento e o orçamento; conquistar vantagem competitiva, liderança de mercado; maximizar o lucro; e alinhar os objetivos individuais com a estratégia corporativa.

\subsection{Análise comparativa das empresas que implantaram um BSCC e as com um BSCU}

Para verificar se há diferenças significantes na implantação do BSC entre as empresas pesquisadas, foi realizado um teste estatístico de comparação entre médias, com bicaudal direta e utilização da tábua de $\mathrm{TC}$ ( $\mathrm{T}$ crítico). Este teste consistiu em verificar se as empresas que implantaram um BSC corporativo com desdobramento para cada tema estratégico (BSCC) e as que implantaram um BSC único para toda a empresa (BSCU) diferenciam das médias calculadas em conjunto para dificuldades, impactos, efeitos e grau de utilização. Foram levantadas duas hipóteses de pesquisa:

H0: as médias são iguais, ou seja, $\mathrm{BSCC}=\mathrm{BSCU}$ H1: as médias diferem, ou seja, BSCC $\neq$ BSCU 
Os resultados calculados separadamente com as médias do BSCC e do BSCU e a análise das hipóteses em nível de significância de 5\% são apresentados na Tabela 6.

Conforme se observa na Tabela 6, de acordo com as médias calculadas separadamente para as empresas que possuem BSCC ou BSCU, a hipótese H0 foi rejeitada para o grupo de dificuldades e de grau de utilização, ou seja, para estes casos as médias do BSCC é superior à média do BSCU. O grupo de impactos e efeitos, apesar de apresentar-se maior, não passa pelo teste de hipóteses, ou seja, a hipótese H0 foi aceita.

O resultado obtido para o grupo de dificuldades e de grau de utilização é completamente aceitável. Tal pode decorrer do fato de que o BSCC é mais complexo, demanda mais trabalho e necessita de um sistema de suporte que integre o BSC corporativo com o BSC das demais unidades. Em contrapartida, as pessoas o entendem melhor, pois se ajusta de maneira mais específica para cada unidade de negócios. Desse modo, pode-se inferir que o BSCC é mais utilizado do que o BSCU, pois seu desmembramento possibilita que mais áreas da empresa o estejam utilizando.

Seguindo esta lógica, as empresas que implantaram o BSCC possuem um instrumento mais complexo, porém, as dificuldades enfrentadas durante este processo são maiores. A implementação da visão estratégica necessita que o BSC corporativo seja interligado com os das unidades de negócio, das equipes, dos indivíduos. Desta forma, há uma interligação entre os sucessivos níveis organizacionais com as mensagens da alta gerência, que são traduzidas de maneira consistente para os níveis mais baixos e vice-versa (LIMA, 2006).

Costa (2001, p. 61) explicita que, sistematicamente, o BSC se caracteriza como um processo gerencial que atua no desdobramento da estratégia de cima para baixo. Kaplan e Norton (1997) descrevem esse processo de alinhamento de cima para baixo, começando seu desenvolvimento pela equipe executiva, a qual deve compartilhar sua visão e estratégia com toda a empresa. A comunicação estratégica e sua vinculação com as metas pessoais geram entendimento e comprometimento compartilhados entre todos os integrantes da organização.

Depreende-se que o processo de desdobramento traz vantagens para a organização, mas também demanda empenho e esforço adicional. Em organizações hierarquizadas, formadas por divisões, unidades de negócios e unidades de serviços compartilhados, o alinhamento é conseguido por meio da conexão do scorecard de alto nível, desenvolvido para a corporação, com aqueles desenvolvidos para as diversas unidades organizacionais.

Segundo Donlon (2003), o desdobramento do BSC para todos os níveis da organização significa sintonizar toda a organização com a estratégia. O desdobramento é muito mais do que um exercício de comunicação da estratégia; representa comprometimento entre equipes e pessoas com o intuito de concentrar recursos e atividades na execução de prioridades mais amplas, abrangendo toda a organização. O desdobramento proporciona a disseminação do BSC em toda a empresa, contribuindo com a execução da estratégia.

Diante dos argumentos favoráveis ao desdobramento do BSC, o fato das médias calculadas para os impactos

Tabela 6. Comparação de médias entre empresas que implantaram BSCC ou BSCU.

\begin{tabular}{|c|c|c|}
\hline Dificuldades & BSCC & BSCU \\
\hline Média & 2,278 & 2,054 \\
\hline Nível de significância & & \\
\hline Hipótese $\mathrm{H}_{0}$ & & \\
\hline Impactos & BSCC & BSCU \\
\hline Média & 2,833 & 2,625 \\
\hline Nível de significância & & \\
\hline Hipótese $\mathrm{H}_{0}$ & & \\
\hline Efeitos & BSCC & BSCU \\
\hline Média & 2,789 & 2,768 \\
\hline Nível de significância & & \\
\hline Hipótese $\mathrm{H}_{0}$ & & \\
\hline Grau de Utilização & BSCC & BSCU \\
\hline Média & 3,196 & 2,910 \\
\hline Nível de significância & & \\
\hline Hipótese $\mathrm{H}_{0}$ & & \\
\hline
\end{tabular}

Fonte: dados da pesquisa. 
e efeitos não terem se diferenciado, mostra-se curioso. Esperava-se que $\mathrm{H} 0$ fosse rejeitada para estes casos também. Uma explicação para isso não ter ocorrido pode estar relacionado ao fato de que, analisando as empresas separadamente, constata-se que o grupo de empresas que implantou o BSCC utiliza o BSC, em média, há menos de três anos, enquanto que as empresas que possuem BSCU, o tem implantado, em média, há seis anos. É possível que essas empresas ainda não tenham sentido os impactos e efeitos na mesma proporção que as empresas que vem utilizando o BSC por um período maior de tempo.

\subsection{Aplicação da ACP e análise das correlações canônicas}

Com o intuito de refinar a análise e encontrar possíveis explicações para os achados da pesquisa, a seguir relacionam-se conjuntos de variáveis por meio da análise de correlações canônicas. No entanto, antes disso aplicou-se a técnica estatística da análise das componentes principais (ACP). Maroco (2003) explica que a técnica da ACP possibilita sintetizar a informação de diversas variáveis correlacionadas em combinações lineares independentes, de modo que possam representar significativamente a informação das variáveis originais.

A finalidade da aplicação da ACP foi a de obter um único escore para um conjunto de subvariáveis. Por exemplo, para a verificação das maiores dificuldades enfrentadas pelas empresas pesquisadas na operacionalização do BSC, listaram-se 26 proposições no instrumento de pesquisa. Os respondentes foram solicitados a indicar o nível de relevância identificado em sua empresa, considerando a escala de 0 a 4 , em que $0=$ Nenhum, $1=$ Pouco, 2=Intermediário, 3=Elevado e 4=Muito elevado.

Depois da tabulação das respostas de cada respondente, aplicou-se a ACP, que resultou no eixo fatorial de cada uma das proposições, demonstrando, assim, qual informação é mais importante entre as proposições. Em seguida, calculou-se o escore total, multiplicando-se a nota atribuída para cada proposição com o seu respectivo eixo fatorial, resultando no escore total das dificuldades de operacionalização do BSC. Assim, a informação se apresenta mais confiável do que na aplicação simples da média entre os respondentes. A ACP possibilita verificar qual informação possui maior importância e maior variabilidade, evidenciando a proposição que melhor explica a variável analisada.

A técnica estatística da ACP foi aplicada em cinco grupos de variáveis: o tempo que a empresa levou para implantar o BSC, as dificuldades relacionadas com a operacionalização do BSC; impactos decorrentes da implantação do BSC; efeitos decorrentes da implantação do BSC; e grau de utilização do BSC. Em cada uma dessas variáveis, buscou-se identificar o eixo fatorial de cada uma das proposições para fins de análise das correlações canônicas.

Mingoti (2005) aduz que a análise das correlações canônicas tem como finalidade principal o estudo das relações lineares existentes entre dois conjuntos de variáveis. Por meio das correlações canônicas, é possível verificar a relação entre dois conjuntos de variáveis, o que não é possível na correlação linear. Essa correlação mede o grau de associação existente entre dois conjuntos de variáveis.

Neste estudo, verificou-se a correlação entre cinco pares de variáveis, utilizando-se o software Statgraphics. Na Tabela 7, apresentam-se os cinco conjuntos de variáveis em que se aplicaram as correlações canônicas, seus respectivos coeficientes de correlação e o $p$-value.

Observa-se, na Tabela 7, que as correlações canônicas, de modo geral, apresentaram-se fortes, visto que seu coeficiente é superior a $70 \%$, exceto a primeira correlação que se apresentou fraca. Destaca-se ainda que, dentre as correlações calculadas, as quatro últimas devem ser consideradas, uma vez que

Tabela 7. Correlações das variáveis do estudo.

\begin{tabular}{|c|c|c|}
\hline Correlações e variáveis & $\begin{array}{c}\text { Correlação } \\
\text { Canônica }(\%)\end{array}$ & P-Value \\
\hline $\begin{array}{l}\text { 1) Correlação entre o tempo de implantação do BSC e as dificuldades } \\
\text { relacionadas com a operacionalização do BSC }\end{array}$ & 17,75 & 0,4674 \\
\hline $\begin{array}{l}\text { 2) Correlação entre as dificuldades relacionadas com a operacionalização do } \\
\text { BSC e os impactos decorrentes da implantação do BSC }\end{array}$ & 96,54 & 0,0000 \\
\hline $\begin{array}{l}\text { 3) Correlação entre as dificuldades relacionadas com a operacionalização do } \\
\text { BSC e efeitos decorrentes da implantação do BSC }\end{array}$ & 96,98 & 0,0000 \\
\hline $\begin{array}{l}\text { 4) Correlação entre as dificuldades relacionadas com a operacionalização do } \\
\text { BSC e o grau de utilização do BSC }\end{array}$ & 96,59 & 0,0000 \\
\hline $\begin{array}{l}\text { 5) Correlação entre o grau de utilização do BSC e os efeitos decorrentes da } \\
\text { implantação do BSC }\end{array}$ & 98,45 & 0,0000 \\
\hline
\end{tabular}

Fonte: dados da pesquisa. 
apresentam $p$-value inferior 0,05. Assim, têm-se quatro correlações de nível forte e que são significativas.

$\mathrm{Na}$ segunda correlação canônica realizada, constata-se um coeficiente de correlação de $96,54 \%$ entre dificuldades de operacionalização e impactos decorrentes da implantação do BSC. Significa que essas variáveis possuem o mesmo comportamento, ou seja, quando aumenta a dificuldade de operacionalização, há aumento no impacto da implantação do BSC. Este resultado já era esperado, uma vez que, quanto maiores são as dificuldades encontradas na operacionalização do BSC, maiores tendem a ser os impactos decorrentes da implantação nas pessoas envolvidas e na empresa como um todo.

A terceira correlação, com um coeficiente de 96,98\% entre dificuldades de operacionalização e efeitos decorrentes da implantação do BSC, indica que quanto maior a dificuldade maior é o efeito de sua implantação. No teste de hipóteses, já se vislumbrava uma possível relação entre dificuldades e efeitos, ou seja, empresas que implantaram um BSC corporativo com desdobramento para cada tema estratégico (BSCC) são submetidas a maiores complexidades do que as que implantaram um BSC único para toda a empresa (BSCU).

Situação idêntica foi percebida na correlação de $96,59 \%$ entre grau de utilização e dificuldades de operacionalização do BSC. Conforme já foi observado no teste de hipóteses, maior grau de utilização está em linha com maiores dificuldades de operacionalização do BSC. Se de um lado há maior complexidade na implantação do BSC, de outro lado espera-se que exista maior sofisticação nos recursos disponibilizados pelo BSC.

Na correlação entre grau de utilização e efeitos decorrentes da implantação do BSC, com um coeficiente de $98,45 \%$, já se esperava esta forte associação entre ambas as variáveis, conforme preconizado na revisão de literatura. Quanto maior o uso deste instrumento, maior deve ser o efeito decorrente na empresa. Kallás (2003) destacou alguns efeitos da correta aplicação do BSC citando vantagens como a integração de medidas financeiras e não financeiras, a comunicação e feedback da estratégia, o vínculo com planejamento e orçamento e maior foco e alinhamento organizacional.

\section{Conclusões}

O estudo objetivou analisar se há diferenças significantes na implantação do Balanced Scorecard (BSC), quanto a dificuldades, impactos, efeitos e grau de utilização, entre as maiores empresas da região sul do Brasil.

Identificou-se que a empresa que possui o BSC implantado há mais tempo, iniciou o projeto de implantação no ano de 1999, e a empresa que implantou mais recentemente iniciou o projeto em 2008. Quanto ao período necessário para sua implantação, percebeu-se que as empresas que concluíram a implantação levaram de um a cinco anos para o término do processo. Sobre a configuração do BSC, verificou-se que oito empresas possuem um BSC único para toda a empresa, e onze empresas possuem um BSC corporativo com desdobramento para cada tema estratégico.

As dificuldades mais relevantes identificadas pelas empresas para operacionalização do BSC são: mobilizar todos a trabalharem com o modelo; definir e tornar claro, para todos, a visão e a missão da organização, obtendo consenso geral em torno da estratégia a longo prazo; identificar indicadores; divulgar e implementar a estratégia em todos os níveis da organização; e alinhar as metas individuais e departamentais com a estratégia das respectivas unidades de negócio.

Toda mudança organizacional passa por dificuldades em seu processo de implantação. Na implantação do BSC, as dificuldades apontadas como mais relevantes estão relacionadas com as pessoas envolvidas no processo. Porém, neste estudo, verificou-se que as dificuldades enfrentadas não foram consideradas como um fator extremamente crítico que pudesse inviabilizar o projeto de implantação. Conforme exposto anteriormente, as empresas que conseguem superar os problemas e adotar o BSC obtêm a recompensa de diferenciarem-se das demais e de concentrar seus recursos em torno de uma estratégia consistente.

O impacto mais representativo decorrente da adoção do BSC, de acordo com os respondentes, são as medidas de desempenho definidas no BSC, por serem capazes de diferenciar a estratégia da empresa, tornando-a única. Esta proposição teve impacto muito elevado, sendo que cinco empresas concordam plenamente. Quanto aos efeitos, os mais relevantes identificados pelos respondentes após a implementação do BSC foram: foco na estratégia, elaboração do planejamento, foco no cliente, análise de desempenho da empresa, motivação e comprometimento das pessoas com o processo da estratégia, e priorização de projetos e ações.

Empresas focadas na estratégia possuem uma organização interna que exige compreensão e comprometimento de todos os funcionários de modo a contribuir para seu êxito. O BSC tenta evitar a falta de envolvimento com o planejamento estratégico à medida que parte da premissa de que a estratégia deve ser uma tarefa de todos. Esse envolvimento contribui com o alinhamento da organização e possibilita o amadurecimento de características individuais que a tornam mais competitiva em relação às demais organizações.

A proposição de uso identificada na pesquisa como a mais relevante está em consonância com o 
motivo mais relevante citado pelos respondentes. O BSC está sendo utilizado pelas empresas pesquisadas como um sistema de gestão estratégica, de medição de desempenho e de apoio à decisão, para esclarecer e traduzir a visão e a estratégia e para alinhar a organização com a estratégia. Os resultados da pesquisa mostram que a utilidade do BSC está vinculada com a operacionalização da estratégia, segundo Rocha (2002) e de acordo com os preceitos identificados por Kaplan e Norton $(1997,2000)$, sobre a utilização do BSC como um sistema de gestão capaz de alinhar a estratégia organizacional.

Constatou-se, por meio do teste de comparação de médias, que as empresas, quando analisadas separadamente quanto à sua configuração, BSCC ou BSCU, apresentam médias maiores nos grupos de dificuldades e grau de utilização. Isto pode decorrer do fato de que o BSCC é mais complexo, demanda mais trabalho e necessita de um sistema de suporte que integre o BSC corporativo com o BSC das demais unidades.

Quanto ao cálculo dos impactos e efeitos, esperava-se que também apresentassem média maior no grupo BSCC, mas não foram encontradas diferenças significativas. Uma explicação que se cogitava para isso não ter ocorrido era o fato de que, analisando as empresas separadamente, verificou-se que o grupo de empresas que implantou o BSCC utiliza o BSC, em média, há menos de três anos, enquanto que as empresas que possuem BSCU, o tem implantado, em média, há seis anos. Deste modo, aquelas podem não ter sentido os impactos e efeitos na mesma proporção, mas isto não se confirmou na análise das correlações canônicas.

Conclui-se, portanto, que há diferenças significantes na implantação do BSC entre as empresas pesquisadas, no que se refere às dificuldades de operacionalização do BSC e ao grau de utilização, e que não há diferenças nos impactos e efeitos ocasionados pelo BSC. Diante das inquietações em consequência dos resultados da pesquisa, recomenda-se que este estudo seja reaplicado em empresas de outras regiões e que os resultados, comparados com os desta pesquisa. Outra sugestão é pesquisar um caso em profundidade para compreender as dificuldades de operacionalização, a utilização, os impactos e os efeitos do BSC.

\section{Referências}

AHLERT, F. C.; KRONMEYER FILHO, O. R. Relações de causa e efeito no diagrama da estratégia do Balanced Scorecard. In: ENCONTRO NACIONAL DE ENGENHARIA DA PRODUÇÃO, 24., 2004, Florianópolis. Anais... Rio de Janeiro: ABEPRO, 2004. CD-ROM.

BONTIS, N. et al. The knowledge toolbox: a review of the tools available to measure and manage intangible resources. European Management Journal, v. 17, n. 4, p. 391-402, Aug. 1999. http://dx.doi.org/10.1016/ S0263-2373(99)00019-5

BURLIM, L. R.; CIA, J. N. S. Transformando estratégia em resultados: um estudo sobre a eficácia do modelo Balanced Scorecard - BSC. In: CONGRESSO BRASILEIRO DE CUSTOS, 14., 2007, João Pessoa. Anais... São Leopoldo: ABC, 2007. CD-ROM.

COSTA, A. P. P. Contabilidade gerencial: um estudo sobre a contribuição do Balanced Scorecard. 2001. Dissertação (Mestrado em Ciências Contábeis)-Faculdade de Economia, Administração e Contabilidade da Universidade de São Paulo, 2001.

DONLON, B. S. Construção de um programa de desdobramento. Balanced Scorecard Report, v. 5, n. 4, July/Aug 2003.

EPSTEIN, M. J.; MANZONI, J.-F. Implementing corporate strategy: from tableau de bord to balanced scorecard. European Management Journal, v. 16, n. 2, p. 190-203, Apr 1998.

FERNANDES, F. P. P.; FONSECA, A. C. P. D. A implantação do Balanced Scorecard em empresas brasileiras sob a perspectiva da cultura nacional. In: CONGRESSO BRASILEIRO DE CUSTOS, 13., 2006, Belo Horizonte. Anais... São Leopoldo: ABC, 2006. CD-ROM.

FERNANDES, A. C. Mapas estratégicos do Balanced Scorecard: contribuições ao seu desenvolvimento. In: ENCONTRO NACIONAL DE ENGENHARIA DA PRODUÇÃO, 22., 2002, Curitiba. Anais... Rio de Janeiro: ABEPRO, 2002. CD-ROM.

GIL, A. C. Como elaborar projetos de pesquisa. 4. ed. São Paulo: Atlas, 2008.

KALLÁS, D. Balanced Scorecard: aplicação e impactos. Um estudo com jogos de empresas. 2003. $184 \mathrm{f}$. Dissertação (Mestrado em Administração)-Universidade de São Paulo, São Paulo, 2003.

KAPLAN, R. S.; NORTON, D. P. The Balanced Scorecard: measures that drive performance. Harvard Business Review, p. 71-79, Jan/Feb 1992.

KAPLAN, R. S.; NORTON, D. P. A estratégia em ação: Balanced Scorecard. Rio de Janeiro: Campus, 1997.

KAPLAN, R. S.; NORTON, D. P. Organização orientada para a estratégia: como as empresas que adotam o Balanced Scorecard prosperam no novo ambiente de negócios. Rio de Janeiro: Campus, 2000.

LIMA, C. R. M. O Balanced Scorecard ajustado para uma universidade fundacional catarinense e desdobrado para sua escola de negócios, cursos e indivíduos. 2006. Tese (Doutorado em Engenharia da Produção)-Universidade Federal de Santa Catarina, Florianópolis, 2006.

MARTINS, G. A.; THEÓPHILO, C. R. Metodologia da investigação científica para ciências sociais aplicadas. São Paulo: Atlas, 2007.

MAROCO, J. Análise estatística: com utilização do SPSS. 2. ed. Lisboa: Sílabo, 2003.

MINGOTI, S. A. Análise de dados através de métodos de estatística multivariada: uma abordagem aplicada. Belo Horizonte: UFMG, 2005.

NORREKLIT, H. The balance on the Balanced Scorecard: a critical analysis of some of its assumptions. Management 
Accounting Research, v. 11, p. 65-88, 2000. http:// dx.doi.org/10.1006/mare.1999.0121

PRIETO, V. C. et al. Fatores críticos na implementação do Balanced Scorecard. Gestão \& Produção, n. 1, p. 81-92, jan./abr. 2006. http://dx.doi.org/10.1590/ S0104-530X2006000100008

REZENDE, J. F. C. O alinhamento estratégico, o Balanced Scorecard e o capital intelectual no Brasil: um estudo empírico nas empresas de maior complexidade e repercussão. 2006. 269 f. Tese (Doutorado em Administração)-Universidade Federal do Rio de Janeiro, Rio de Janeiro, 2006.

REIS, G. V.; COLAUTO, R. D.; PINHEIRO, L. E. T. Proposta de adaptação do Balanced Scorecard para órgãos públicos: um enfoque na secretaria geral de administração (Segedam) do tribunal de contas da união. In: CONGRESSO BRASILEIRO DE CUSTOS, 14., 2007, João Pessoa. Anais... São Leopoldo: ABC, 2007. CD-ROM.

RICHARDSON, R. J. Pesquisa social: métodos e técnicas. 2. ed. São Paulo: Atlas, 1989.

ROCHA, A. C. B. Configuração de um sistema de avaliação de desempenho alicerçado no Balanced Scorecard para uma indústria de confecções de porte médio. 2002. Dissertação (Mestrado em Engenharia da Produção)-Universidade Federal de Santa Catarina, Florianópolis, 2002.

ROCHA, A. C. B.; BEUREN, I. M. Aplicação do Balanced Scorecard em uma empresa de porte médio de soluções integrais em uniformização. In: CONGRESSO BRASILEIRO DE CUSTOS, 9., 2002, São Paulo. Anais... São Leopoldo: ABC, 2002. CD-ROM.

SAHELI, S. Balanced Scorecard: o exemplo da Suzano. In: CONGRESSO BRSILEIRO DE CUSTOS, 9., São Paulo. Anais... São Leopoldo: ABC, 2002. CD-ROM.

SOARES JUNIOR, H.; PROCHNIK, V. Experiências comparadas de implantação do Balanced Scorecard no Brasil. In: CONGRESSO LATINO AMERICANO DE ESTRATÉGIA, 17., Itapema. Anais... Itapema: CLADEA, 2004. CD-ROM.

SCHNEIDERMAN, A. M. Why balanced scorecards fail. Journal of Strategic Performance Measurement, p. 6, 1999. Special Edition.

TEIXEIRA, F. S. Mensuração do grau de eficácia do Balanced Scorecard em instituição privada de ensino superior. 2003. Dissertação (Mestrado em Ciências Contábeis)-Universidade de São Paulo, São Paulo, 2003.

VERGARA, S. C. Projetos e relatórios de pesquisa em administração. 3. ed. São Paulo: Atlas, 2000. 